\title{
LANGUAGE OF LEARNING AND TEACHING AS A BARRIER TO EFFECTIVE IMPLEMENTATION OF CAPS: NARRATIVES OF GRADE 10 LIFE SCIENCES TEACHERS IN THE NORTH WEST PROVINCE
}

Florah Teane

University of South Africa

\begin{abstract}
The study sought to provide information about the experiences of Life Sciences teachers in the implementation of the Curriculum and Assessment Policy Statement (CAPS) using English as the language of learning and teaching (LoLT). Life Sciences, as a subject within the Further Education and Training (FET) band, underwent a series of policy changes over a very short period. The teachers in the Bojanala East District in the North West Province were faced with the challenge of implementing the new policy known as CAPS using English as LoLT. A qualitative research design was employed for the study. The researcher used a purposeful sampling technique to select 33 Grade 10 Life Sciences teachers as participants. Data were collected using one-on-one interviews, focus group interviews and document analysis to investigate the performance of Grade 10 to 12 learners in Life Sciences over a period of three years. Findings of this research indicate that the use of English as LoLT in teaching Life Sciences prevented learners from sufficiently understanding the subject. In addition, learners seem to struggle with new terminology as implemented by the policy changes.
\end{abstract}

KEYWORDS: English, language barrier, learner performance, Life Sciences, teachers, teaching and learning

\section{INTRODUCTION}

Historically, in the South African context, the issue of language became 'embroiled in the political and status struggle of the English and Afrikaans speaking communities' (Giliomee, 2004: 34). The study reported on in this article focused on the effect of the use of English as LoLT in the teaching and learning of the Grade 10 CAPS Life Sciences content. Like the majority of South African teachers, Life Sciences teachers in the Bojanala District work in classrooms where English is not the first language of either the teachers or learners (Setati, Adler, Reed and Bapoo, 2002: 129). This has created a situation in which learners must first understand the LoLT (Hewson \& Ogunniyi, 2011) in order to understand the Life Sciences terminology. Therefore, during the teaching and learning process and to acquire the necessary knowledge, learners must first translate the language of instruction into their home language (Gudula, 2017). The situation was exacerbated by a plethora of educational policies in the postapartheid era, in an endeavour to deal with the legacy of the apartheid regime. Life Sciences at Grade 10 to 12 level in the Further Education and Training (FET) band was one of the subjects 
that saw enormous changes, with topics being shifted from one grade to another (Johnson, Dempster and Hugo, 2015). Thus, the study sought to answer the research question, 'What are the experiences of Life Sciences teachers during the teaching of the CAPS Grade 10 Life Sciences syllabus using English as LoLT?'

In the South African context, English became the dominant international language (Hall \& Cook, 2012) of learning and teaching in this country, leading to the need to acquire English proficiency for good performance in education (Probyn, 2009). Prinsloo, Rogers and Harvey (2018) support Probyn (2009) in stating that in order for learners' academic achievement in science to improve, they need to be proficient in the language of learning and teaching (LoLT). Even though in the view of Wellington and Osborne (2001: 1), learning the language of science makes the teaching of science subjects difficult, in the South African context the situation has been worsened by the educational jargon associated with the current CAPS policy. According to the current policy (CAPS), Grade 1 to 3 learners are taught in their mother tongue, and from Grade 4 onwards, learners are taught in English (DBE, 2011: 8). The study reported on here focused on the implementation of CAPS using English as LoLT in the subject Life Sciences at Grade 10 level given that learning and practicing a language takes time to manifest itself (Pfeiffer 2018: 73). Earlier research conducted by Ferreira (2011: 109) revealed that as a result of learners' lack of fluency in the LoLT, they resorted to memorisation. In similar vein, a study by De Villiers (2011) revealed that as a result of difficult terminology, learners found Grade 10 Life Sciences content to be the most difficult. Fisher, Moody and Wandersee (2000: 29) provide support for this, describing the Life Sciences/Biology content as extensive, highly complex and often poorly structured. The assertion by Gibbons (2015: 8) that even a fluent first-language speaker of English will not be proficient in every possible context, prompted the researcher to look into the effects of using a second language in the learning and teaching of Life Sciences as a subject. As there is a lack of research and literature about the effect of language as a barrier to the implementation of the CAPS policy, specifically the Life Sciences Grade 10 syllabus, the study discussed here was undertaken with a view to bridging that gap.

The rest of this article proceeds as follows. First, it provides the theoretical framework that underpins the study, discussing the empowerment theory and its implications. Second, the methodology that includes research design, population, sampling and data collection techniques is discussed. Third, a detailed presentation of results is given, highlighting the implications for future research on language as a barrier to understanding subject content. The article concludes by turning to several broader implications of these arguments for policy-making in development.

\section{THEORETICAL FRAMEWORK}

The study concerned language as a barrier to effective implementation of the CAPS curriculum, in a situation in which a lack of language proficiency on the part of Grade 10 learners hinders them in acquiring meaning and understanding of the Life Sciences subject content. This is underpinned by Ausubel's subsumption theory (Ausubel, 1962) in which it is proposed that in human beings, learning takes place through a meaningful process of relating new events or items to already existing cognitive concepts. Ausubel (1962) refers to this as hanging new items on existing cognitive pegs, where the new material is anchored on already established entities in the cognitive structure. When such a cognitive structure exists in the human mind, the new material becomes appropriately subsumed under a more inclusive conceptual system. Therefore, to 
comprehend the Life Sciences content learners have to first master English, because appropriate language skills enable learners to engage successfully in argumentation (Hewson \& Ogunniyi, 2011). The lack of such language skills (Ausubel's, cognitive pegs 1962:168) has a negative impact on the teaching of science subjects (Meyer \& Crawford, 2009). The LoLT skills serve as the cognitive structure that enables the learners to comprehend the Life Sciences terminology easily because they serve as a base on which new knowledge can be built (Caro, SandovalHernandez \& Ludtke 2014: 438).

Meaningful learning in the teaching and learning situation becomes possible if learners are able to relate the new information to information they already have; Ausubel terms this 'the cognitive structure of knowledge'. Brown (1972: 93) asserts that for a new problem to be understood, human beings need to have basic knowledge to help them understand it. When the learners have what Ausubel calls 'anchoring ideas', which consist of prior experiences and cognitive structure, they are able to interact with new material with understanding. In learning any new Life Sciences topic, prior knowledge is crucial for mastering the new information (Cakir, 2008). This means that in order for Grade 10 learners to understand the new content in CAPS, they must have the necessary language proficiency, which will help them unpack the new educational jargon contained in the Grade 10 syllabus. Brown (1972: 96) refers to the situation in which prior knowledge benefits the learning task as a positive transfer. Since Life Sciences as a subject is taught in English, learners who have already acquired English language skills will be able to interact with the Life Sciences content with understanding. However, the opposite occurs when the learners' previous knowledge does not link with the new content. Brown (1972: 95) regards it as interference, for instance, 'the interference effects of the first language on the target LoLT'. Interference could also be caused by a situation in which a particular topic in Life Sciences is taught without learners having the basics, for instance, an understanding of the terminology.

According to Ausubel (1962: 168), the inability to relate new content to an existing schema leads to rote learning, which he defines as 'the process of acquiring material as discrete and relatively isolated entities that are relatable to cognitive structure only in an arbitrary and verbatim fashion, not permitting the establishment of (meaningful) relationships' . Prinsloo et al. (2018: 2) suggest that the only way to eliminate rote learning is to obtain scientific literacy, in this case biological terms, with the teacher playing an important role in teaching learners how to read and write these (Fung \& Yip, 2014). The role of the teacher is to help learners acquire scientific literacy, for instance biological terminology, to prevent them from storing items as isolated blocks with no function in the building of a structure and no relationship to other blocks (Gonzalez-Howard \& McNeill, 2016). Information stored this way will lead to memorisation of content, which is easily forgotten because over time the items become progressively less identifiable as entities in their own right until they are no longer available, having been forgotten (Ferreira, 2011: 109). If learners try to memorise knowledge content that they have not understood during the teaching and learning of Life Sciences, remembering the content will be difficult. Forgetting also applies to second-language learning, since, as Brown (1972) points out, certain aspects of language are more susceptible to being forgotten than others: for instance, lexical items may be more easily lost to memory than idioms.

Conversely, a meaningfully learnt subsumed item has far greater potential for retention. A learning situation becomes meaningful if learners have background knowledge of what is to be learnt. If learning is meaningful, learners are easily able to remember learning material when the 
need arises. The acquisition of language proficiency, which according to Prinsloo et al. (2018), needs to be imparted by the teacher, will enhance the understanding of Life Sciences content. If the learners lack the language skills, teaching using English as LoLT prevents meaningful learning, and so learners are unable to remember the content during examination and tests, and therefore perform poorly.

This theory has educational implications for the teaching and learning of the Life Sciences subject content using English as a second language because it emphasises the importance of acquiring language proficiency in dealing with Life Sciences content. Language skills allow understanding of Life Sciences content because learners understand what they are being taught. Lack of such skills leads to misunderstanding of concepts, and most learners resort to rote learning. Content learnt by rote is easily forgotten, and cannot be applied in the assessment tasks.

\section{LITERATURE REVIEW}

Language proficiency directly affects the teaching and learning of subject content for secondlanguage learners (Elsworth, 2013). There is a growing debate on what leads to easy mastery of second language learning. Hugo (2017: 118) reports that some parents believe that the environment in which learners are brought up plays a major role and such parents would prefer schools where English is regarded as first language. Some studies have shown that in South Africa, use of learners' first language as LoLT in Grade 1 to 3 has assisted learners in studying in English later on (Taylor \& Coetzee, 2013; Taylor \& Von Fintel, 2016). Conversely, however, Spaull (2013) supports Hugo (2017) by stating that learners who attend schools where English is the LoLT from the onset of their schooling stand a better chance to acquire proficiency in the language. According to Spaull (2013) the proficiency in English of these learners can be attributed to the fact that the learners are from affluent families where they are frequently exposed to the language on television and speak the language with their parents. Caro et al (2014: 438) suggest that learners who have access to English books at home master the English language more easily. Hall and Cook (2012: 271), support Spaull (2013) and Hugo (2017) by stating that a new language is best taught and learnt monolingually, meaning language proficiency can be achieved when only one language is used to teach learners, i.e. not using the learners' mother tongue and the new language concurrently. This is often called code-switching. However, these authors add that the monolingual teaching of English has inhibited the development of bilingual and bicultural entities and skills that are needed by most learners. Conversely, Babaci-Wilhite (2013) holds the view that learning becomes effective when the medium of teaching and learning is a local language, and so code-switching is recommended as an alternative measure enabling teachers to compensate for learners' apparent lack of understanding (Hall \& Cook, 2012; Gudula, 2017). Rose \& Van Dulm, (2006: 8) define codeswitching as using two or more languages alternatively during the teaching and learning process. In the South African context, especially schools in the North West province, teachers use Setswana as a language of complicity to overcome problems of English-medium classroom interaction and to demonstrate empathy or show solidarity with the learners (Hall \& Cook, 2012: 286). In the study conducted by Gudula (2017), code-switching was shown to be used as a way to enforce understanding of the language of science.

Literature has revealed that most of the learners taking Life Sciences come to class with background information that does not match with science (Cakir, 2008; Mdolo \& Doidge, 2011). 
Cakir (2008) therefore recommends the use of a constructivist approach involving social interactions among learners, which has produced good results in terms of constructing biology knowledge by learners. Fisher et al (2000: 4) state that students do not have metacognitive skills that will foster independent study. Thus, most learners perform poorly in such tasks because they do not understand the questions and are unable to express themselves in English. To boost selfdirected learning, Cotterall and Murray (2009: 42) suggest a well planned learning content as a prerequisite for the development of metacognitive skills. Lederman, Lederman, Kim and Ko (2006) explain that teachers find it difficult to create a conducive classroom environment where learners' understanding of science is enhanced, and that this is exacerbated by teaching using learners' second language as LoLT.

\section{METHODOLOGY}

This research was based on the research philosophy of interpretivism and constructivism, which, according to Kipo (2013: 261) are 'multiple realities or truths based on an investigator's construction of reality (subjectivity of reality is an indication that reality is a social construct and keeps changing)'. The study was interpretive because it provided detailed in-depth data that permit critical consciousness by the reader (Denzin \& Lincoln, 2013: 147).

The research sought information about the effect of language as a barrier to policy implementation. In this study a qualitative research design was used, focusing on participants' perspectives and experiences, through triangulation where multiple sources are used to provide rich data (Yin, 2012: 178). Since the aim of the study was to ascertain how Life Sciences teachers experienced the implementation of Life Sciences content using English (a second language) as LoLT, a case study was selected as the best approach, because it operates within certain bounds (Yin, 2012: 7).

\section{Population and sampling}

The population of the study comprised approximately 300 (100\%) Life Sciences teachers from the Bojanala District in the North West province. Most of the schools in the district are in rural areas, and of the 96 schools offering Life Sciences as one of their subjects, only 35 are former model $\mathrm{C}$ schools with facilities to provide a conducive teaching and learning environment. During the period of the research, the Bojanala District consisted of six area offices, each with a Life Sciences subject advisor. The researcher engaged the services of the subject advisors to access contact details of teachers, who were then approached individually. Using purposeful sampling, the researcher was able to select a sample of 33 teachers who had taught the subject for between 22 and 30 years and were between 40 and 55 years of age. Age was used as a variable in this study to engage only teachers who had experienced all four Life Sciences policy changes, because their experience in teaching the subject was needed to provide valid and reliable information. Of the 33 participants, 19 were female and 14 were male. Only three participants taught at well-resourced schools, with the remaining 30 participants being teachers who taught at schools lacking well-resourced laboratories and libraries; the researcher encountered a greater willingness among teachers at poorly resourced schools to take part in the study. 


\section{Ethical considerations}

The researcher applied the ethical clearance process of informed consent as well as privacy and confidentiality. Participants were informed about the nature and consequences of the research and confidentiality was assured as the primary safeguard against unwanted exposure. All participants signed a consent form, but they were also made aware that they had the right to withdraw from the study at any time.

\section{Data collection strategies}

The researcher used two focus groups, 20 one-on-one interviews and document analyses to collect data. A semi-structured interview format was used in the one-on-one interviews and the two focus groups, because this format allows the researcher to gather more information (Hoets, 2012). The two focus groups consisted of six and seven participants respectively. Interviews were held during the week and weekend at a place suitable to the respondents, namely at school, at home and in a community hall. The researcher developed the interview questionnaires on the basis of clarity-seeking questions that addressed the focus of the study by relating to learners' behavioural characteristics that demonstrated a lack of language proficiency. A journal was used to record some information while the participants were responding to questions and a voice recorder was used to record information that the researcher might have missed. The researcher asked questions and used probing to gather more information. With the help of the district coordinator, the researcher was able to access the district's Life Sciences results pertaining to a period of three years $(2016-2018)$.

\section{Data analysis}

The researcher engaged in the thematic analysis of data using the Saldana (2016:8) method of qualitative analysis. First, data was broken down into codes. Saldana (2016: 8) describes coding as the 'critical link' between data collection and the explanation of its meaning. Coding was therefore done through the identification of patterns which demonstrated habits, salience, and importance in people's daily lives. Thereafter, data were categorised by grouping, reorganising and linking the codes in order to consolidate meaning. In the end, themes emerged from these categories and were used to discuss the findings of the research. The following themes emerged from analysis of the data:

Indications of lack of learner language proficiency, the abstract nature of the CAPS Grade 10 Life Sciences content, and the intervention strategies applied by teachers to mitigate learners' language difficulties.

With regard to the document analyses, the researcher compiled results for Grade 10 to 12 separately in a table. Different colours were used to distinguish between the grades to enable the reader to observe trends in performance. Four area offices' (A_D) Grade 10-12 Life Sciences' end of the year results (2016-2018) were analysed to show general performance in the subject. The pass percentages were tabled for the three Grades (10-12) in all the area offices and the influence of language in performance was observed between rural and urban schools.

The purpose of the study was to share information on the effect of using a second language (in this case English) for the implementation of CAPS. The main research question therefore was: Per Linguam 2019 35(3):92-105 http://dx.doi.org/10.5785/35-3-859 
What are the experiences of Life Sciences teachers during the teaching of the CAPS Grade 10 Life sciences syllabus using English as LoLT?

The following sub-questions were formulated:

- Which language-related behaviours do the Grade 10 Life Sciences learners display?

- How does CAPS Grade 10 educational terminology add to the LoLT?

- Which coping mechanisms are used by teachers and learners to deal with the language gap?

The data collected was analysed and interpreted in the section below which deals with the findings and discussions of this study.

\section{FINDINGS}

\section{Indications of lack of learner language proficiency}

Participants indicated that the Grade 10 Life Sciences learners demonstrated gaps in their use and understanding of the LoLT by being unable to express themselves either verbally or in written form. Teachers indicated that the Grade 10 learners were not actively involved during the teaching and learning process and teachers were, therefore, uncertain as to whether learners understood the topic taught or not.

Participant 1 reported: Learners are not responding to questions and one could not tell whether they are rebellious or they do not understand. It seems the normal chalkboard method does not suit them because, they neither ask nor respond to questions.

Participant 2 stated: It is difficult to read what the Grade 10 learners have written in their books. Sometimes I will call them to read and explain the meaning of what they have written, but they too cannot explain what they wrote.

One participant indicated that he was worried about learners' inability to express themselves using English words. The participant, therefore, tested their reading ability by asking them to read aloud.

Participant 12 said: One day, during a Life Sciences period, I was introducing a new topic and asked the learners to open their textbooks and read silently. After 15 minutes, I chose learners randomly and asked them to read aloud and I realised they were unable to pronounce words properly which means they do not understand.

One of the formative assessment tasks in Grade 10 is an assignment or project. To complete the tasks, learners need to do research to be able to answer the questions in the assignment. Participants indicated that learners are not doing justice to this task, because they either write nothing at all, or copy one another's responses.

Participant 3 commented: Because learners cannot do individual work, I usually group them so that they submit group work. But grouping them did not solve the problem because they still did not do quality work or half the class would submit the same assignment.

Participants also revealed that learners were performing very badly in monthly tests and the examination at the end of the year. 
Participant 4 reported: I am teaching Life Sciences Grade 10 to 12 and the Grade 10 learner performance is shocking. Performance in SECTION A questions, where only one word is required is better, but questions that tests understanding, application and evaluation and synthesis cognitive levels are poorly answered because learners cannot express themselves.

\section{Abstract nature of the CAPS Grade 10 Life Sciences content}

Participants indicated that the abstract nature of the CAPS Grade 10 content has worsened the situation whereby learners find it difficult to understand the content. They explained that there were very difficult Life Sciences topics, which, prior to CAPS, had formed part of the Grade 12 syllabus. The participants viewed these topics as being of a high standard for a Grade 10 learner, and needing prior knowledge.

Participant 5 said: The first topic in Grade 10 which is about organic and inorganic compounds was once taught in Grade 12 during the interim core syllabus policy change. The science language in the topic is complicated, which needs a mastery of biological terms. Evolution topic also starts in Grade 10 and learners are struggling to understand it.

Participants also indicated that numerous topics are covered in Grade 10, and that LoLT problem prevents the teacher from finishing the syllabus effectively because learners take time to understand. Teachers claimed that they seldom finish or do justice to all topics because learners take too much? time to master a topic.

Participant 6: The Grade 10 topics are many and it is impossible to cover them adequately because I am moving very slow because learners do not understand.

Participants also indicated that they are forced to rush the topics even when learners show signs of not understanding because of the CAPS pacesetter document, which sets the start and finish dates of topics. Certain topics must have been taught by the end of a term, and all learners, regardless of their ability, are expected to master the content, after which a quarterly test is administered.

Participant 7 commented: Only learners who are proficient in the LoLT are able to understand the Life Science content and they obtain good marks in the tests. But the majority of learners are struggling and hence poor performance in the quarterly tests and end of the year examination.

\section{Intervention strategies applied by teachers to mitigate learners' language difficulties}

Participants explained that they applied certain strategies, such as code-switching, to deal with the language problem.

Participant 8 said: Whenever I use Setswana language to explain concepts, the learners' faces brighten up to show that they understand and they will start asking questions. The problem comes when they are expected to write, they have to start by translating the English words to Setswana then use LoLT to write, something which is difficult for them.

Participants also described how they grouped learners so that each group included two learners with good language proficiency to help explain concepts to the other learners. 
Participant 9 stated: Group work has helped other learners to understand. I have realised that grouping learners of the same language proficiency together does not work, I saw it when they were doing assignments. I have now mixed learners of different abilities and it has worked.

In order to meet the timelines, participants indicated that they created extra time for the learners and gave them extra work to practise.

Participant 10 said: I offer extra classes during school holidays to allow learners to understand. For each topic, I have developed a list of biological terms with meanings and I encourage all learners to read at home and master them.

Findings also indicated that learners themselves had developed strategies to deal with their poor performance in LoLT, including rote learning. Participants indicated that rote learning helped learners to answer questions for which just a one-word answer was required, that is, the questions in SECTION A of the examination paper.

Participant 11 said: Learners performed well in SECTION A questions because they memorised certain biological terms. But they do not fare well in discussion questions because memorisation makes them to forget other important information.

\section{DOCUMENT ANALYSES}

Grade 10 to 12 Life Sciences results were requested from the district office; the table 1 below shows the subject performance trend from four area offices over three years $(2016-2018) .75 \%$ of the schools resorting under area offices A and B were in urban areas, whereas all the schools resorting under area offices $\mathrm{C}$ and $\mathrm{D}$ were in rural areas.

Table 1 Analysis of Grade 10 - 12 Life Sciences results (2016 - 2018)

\begin{tabular}{|l|l|l|l|l|l|l|l|l|l|l|l|}
\hline & \multicolumn{2}{|c|}{$\mathbf{2 0 1 6}$} & & \multicolumn{2}{c|}{$\mathbf{2 0 1 7}$} & \multicolumn{2}{c|}{$\mathbf{2 0 1 8}$} \\
\hline $\begin{array}{l}\text { AREA } \\
\text { OFFICE }\end{array}$ & $\mathbf{1 0}$ & $\mathbf{1 1}$ & $\mathbf{1 2}$ & & $\mathbf{1 0}$ & $\mathbf{1 1}$ & $\mathbf{1 2}$ & & $\mathbf{1 0}$ & $\mathbf{1 1}$ & $\mathbf{1 2}$ \\
\hline A & 56.7 & 68 & 89.4 & & 40.3 & 68 & 87 & & 48 & 54 & 84 \\
\hline B & 47.8 & 53.57 & 86.01 & & 44.2 & 55.57 & 80.23 & 59 & 60.83 & 82.23 \\
\hline C & 38.9 & 48.3 & 74 & & 44.9 & 60.83 & 70.6 & & 43.2 & 58 & 68 \\
\hline D & 35.8 & 55.2 & 78 & & 40.3 & 49 & 75.5 & & 40 & 77 & 77.2 \\
\hline & & & & & & & & & & & \\
\hline AVERAGES & $\mathbf{4 4 . 8}$ & $\mathbf{5 6 . 2 6}$ & $\mathbf{8 1 . 8 5}$ & & $\mathbf{4 2 . 4 2}$ & $\mathbf{5 8 . 3 5}$ & $\mathbf{7 8 . 3 3}$ & & $\mathbf{4 7 . 5 5}$ & $\mathbf{6 2 . 4 5}$ & $\mathbf{7 7 . 8 5}$ \\
\hline & & & & & & & & & & & \\
\hline
\end{tabular}

Source: Bojanala District office

The above analysis indicates that there is no significant difference in performance between area offices with schools in urban areas and those with schools in rural areas. In some instances, performance in rural area schools was higher than in urban area schools; for example, in 2017, Grade 10 performance in the schools falling under area office A (40.3) was lower than that in the schools falling under area office $\mathrm{C}$ (44.9). The general trend is that the percentage pass for Grade 10 remained at 40\%, whereas Grade 11 performance ranged from 50 to 60\%, and Grade 12 performance ranged between 70 and $80 \%$.

\section{DISCUSSION}

Per Linguam 2019 35(3):92-105

http://dx.doi.org/10.5785/35-3-859 
The findings of this study refute the assertion made by Taylor and Coetzee (2013) that South African learners stand a better chance of acquiring English language skills through their orientation to the language from Grade 4 onwards. The findings of this study also do not support those of Taylor and Von Fintel (2016: 88), who state that receiving first-language instruction (rather than English instruction) in Grade 1, 2 and 3 leads to better English proficiency in the subsequent grades. From the findings of this study, it became evident that even up to the FET level learners seem to lack the basic language skills to understand English; participants indicated that learners were unable to read English with understanding. To a certain extent the findings of the study reported on in this article support the views of Gibbons (2015), who suggests that teaching and learning using English as a second language is very difficult, and that even a fluent first-language speaker of English will not be proficient in every possible context. Gibbons's assertion alludes to the fact that no matter how much training English second-language learners receive, they will nevertheless experience problems if teaching and learning is conducted using English as the LoLT. The experiences of the Life Sciences teachers in this study confirm this; one would not expect a Grade 10 learner to lack English language proficiency, given that in South Africa, English is used as LoLT as early as Grade 4. The use of a local language, as Babaci-Wilhite (2013) observes, will enhance the teaching and learning process, and this means that even if teaching using English starts early, English language proficiency remains a problem. The participants of this study indicated that learners from the Bojanala District, of whom the majority were from impoverished rural backgrounds, experienced difficulties in learning the Life Sciences content because of poor proficiency in English as a second language. The geographic location of the learners' households (Bojanala District) meant that the parents of roughly $80 \%$ of the learners were unable to provide support in terms of the provision of English books at home or speaking English to them to fine-tune their English language skills. This meant that, as suggested by Spaull (2013), the socio-economic background of these learners hindered them from acquiring the language skills that would have assisted them in mastering the language. . Language acquisition needs training and practice that cannot be offered by teachers alone, a point raised by Fung and Yip (2014), and the home environment has an important role to play in nurturing that particular skill. Participants of this study indicated that extra work in the form of terminology was given to learners to practise at home, and that this brought about some improvement in performance, although this related to one-word answer questions only.

The results of this research indicate that learners' lack of anchoring ideas (Ausubel, 1962) made the Life Sciences teaching and learning process extremely difficult. Anchoring ideas in the form of basic English grammar were not displayed by learners because they could not spell English words correctly, nor could they read English words with understanding. This gave rise to poor performance in individual tasks such as assignments, projects and written tests (Elsworth, 2013). As an intervention to enhance learner understanding and participation, participants grouped learners with varying degrees of language proficiency together. The strategy of grouping learners is in line with Cakir's (2008) constructivist approach in that it provided an environment fostering social interaction among learners. In the groups formed, those learners with better language skills enhanced argumentation because of their proficiency in English language. This practice could be applied in science classes to enable all learners to achieve the learning outcomes; potentially this could contribute to eliminating rote learning, which results in poor performance in tests and assignments. 
The research findings also reveal that lack of language proficiency contributed to what Prinsloo et al. (2018) term lack of science literacy, which was exacerbated by the abstract content and terminology of CAPS Grade 10 Life Sciences (Ferreira, 2011; De Villiers, 2011). Participants mentioned that a plethora of policy changes in South Africa have led to the shifting of topics from one grade to another, which was one of the factors in this study that made the teaching of Grade 10 Life Sciences content difficult, as learners lacked the language skills to deal with topics for which they did not have the background. These topics (participants mentioned organic and inorganic compounds, and evolution) involved abstract terminology (referred to by Wellington and Osborne (2001) as the language of science) that hindered learners' understanding of the Life Sciences content. The abstract nature of the Life Sciences content and learners' lack of English language proficiency hindered meaningful learning (Ausubel, 1962), and learners therefore resorted to rote learning as an alternative measure. Consequently, they stored information as isolated blocks that served no function in the building of a structure and had no relationship to other blocks (Gonzalez-Howard \& McNeill, 2016), and as a result they forgot the content very easily. Participants reported poor performance on the part of CAPS Grade 10 learners because teachers had to rush the syllabus to meet deadlines prescribed by the Grade 10 Life Sciences pacesetter document and because learners were slow to master the content because of the language gap. Giving learners homework to do and offering extra classes definitely improved learner performance, which suggests that this is a teaching strategy that other teachers teaching other subjects could apply to improve poor performance by learners.

The results of this research have shed light on the importance of code-switching by teachers as an alternative measure to solve the language problem. Although authors Taylor and Von Fintel (2016) favour the use of learners' first language, the results of this research indicate that codeswitching had short-term advantages. During teaching, teachers used this mechanism to explain concepts, but while writing tests and examinations, learners were unable to translate what they understood in their first language into the LoLT. In the population from which the sample was derived, code-switching caused something of a dilemma (Ferreira, 2011), because the teachers translated into Setswana in a class where only $30 \%$ of the learners were Setswana speaking, and the majority of the learners spoke other African languages as their first language. One might well ask whether or not code-switching helped those learners, and certainly in the case of some learners who were not Setswana speaking, it led to a negative transfer of information; this, according to Brown (1972), refers to interference when a previous item is incorrectly associated with an item to be learnt. Students who were not Setswana speaking were likely to become even more confused, because they needed to understand Setswana before being able to understand the translated information. The results of this research suggest that code-switching would only be effective if a first language common to all learners were used, which is practically impossible. The use of English as a lingua franca covers all learners - the only challenge would lie in using it in a context in which learners lack a proper foundation in the language.

From document analyses, it became evident that lack of resources did not seem to be a major factor in the performance in the schools in this study, instead the results seem to indicate that LoLT was a bigger factor. This was demonstrated by the fact that learner performance in rural schools was on occasion higher than that in urban schools. The abstract nature of the Grade 10 syllabus and learners' poor English language proficiency hindered meaningful learning, and seemed to contribute to poor performance in the grade. 


\section{CONCLUSION}

The research paper discussed language as a barrier during the implementation of CAPS curriculum policy. Learners' behavioural characteristics arising from poor English language proficiency as manifested in the inability to read and write using English as LoLT made the teaching of CAPS Grade 10 Life Sciences content difficult. Poor learner performance, teachers not being able to complete the work schedules, and learners adopting rote learning as an alternative measure, and which caused them to forget the content easily, are some of the difficulties arising from language as a barrier to teaching and learning. Therefore, the following suggestions are made:

- The Department of Education is advised to put systems in place to make sure that both teachers and learners master English language skills.

- Code-switching must be discouraged because to those learners who do not speak the African language used to code-switch it brings more confusion.

- Professional development in the form of in-service training will equip teachers with skills to overcome the language barrier.

- Revise the Grade 10 CAPS Life Sciences content

$\bullet$

The South African government's adherence to the suggestions above will ease the implementation of CAPS.

\section{REFERENCES}

AUSUBEL, DP. 1962. A subsumption theory of meaningful verbal learning and retention. The Journal of General Psychology, 66(2): 213-224.

BABACI-WILHITE, Z. 2013. A study of language of instruction and quality learning in Tanzania. Russian-American Education Forum: An Online Journal, 5(1).

BROWN, HD. 1972. Cognitive pruning and second language acquisition. The Modern Language Journal, 56(4): 218-222.

CAKIR, M. 2008. Constructivist approaches to learning in science and their implications for science pedagogy: A literature review. International Journal of Environmental and Science Education, 3(4): 193-206.

CARO, DH, A SANDOVAL-HERNANDEZ \& O LUDTKE. 2014. Cultural, social, and economic capital constructs in international assessments: An evaluation using exploratory structural equation modelling. School Effectiveness and School Improvement, 25(3): 433450. https://doi.org/10.1080/09243453.2013.812568

COTTERALL, S \& G MURRAY. 2009. Enhancing metacognitive knowledge: Structure, affordances, and self. System, 37(1): 34-45.

DENZIN, NK \& YS LINCOLN. 2013. The Sage handbook of qualitative research. Fourth Edition. Thousand Oaks: Sage.

DBE (DEPARTMENT OF BASIC EDUCATION). 2011. English First Additional Language (EFAL). Curriculum and Policy Statement (CAPS). Pretoria: Department of Basic Education. 
DE VILLIERS, R. 2011. Student teachers' views: what is an interesting Life Sciences curriculum? South African Journal of Education, 31(4): 535-548.

ELSWORTH, S. 2013. Do language barriers affect student performance in school? Available from Demand Media: http://everydaylife.globalpost.com/language-barriers-affect-student performance-school-5911 html [Accessed: 25 June 2015]

FERREIRA, JG. 2011. Teaching Life Sciences to English second language learners: What do teachers do? South African Journal of Education, 31(1): 102-113.

FISHER, K, JH WANDERSEE \& DE MOODY. 2000. Mapping biology knowledge (Vol. 11). Springer Science \& Business Media. London: Kluwer Academy.

FUNG, D \& V YIP. 2014. The effects of the medium of instruction in certificate-level physics on achievement and motivation to learn. Journal of Research in Science Teaching, 51(10): 1219-1245. https://doi.org/10.1002/tea.21174.

GIBBONS, P. 2015. Scaffolding language, scaffolding learning: Teaching English language learners in the mainstream classroom (2nd ed.). Portsmouth, NH: Heinemann

GILIOMEE, H. 2004. The rise and possible demise of Afrikaans as a public language. Nationalism and Ethnic Politics, 10(1): 25-58.

GONZALEZ-HOWARD, M \& KL MCNEILL. 2016. Learning in a community of practice: Factors impacting English-learning students' engagement in scientific argumentation. Journal of Research in Science Teaching, 53(4): 527-553. https://doi.org/10.1002/tea.21310

GUDULA, Z. 2017. The influence of language on the teaching and learning of Natural Sciences in Grade 7. Master in Science Education Dissertation. University of Western Cape.

HALL, G, \& G COOK. 2012. Own-language use in language teaching and learning. Language Teaching, 45(3): 271-308.

HEWSON, MG \& MB OGUNNIYI. 2011. Argumentation-teaching as a method to introduce indigenous knowledge into science classrooms: Opportunities and challenges. Cultural Studies of Science Education, 6(3): 679-692.

HOETS, H. 2012. Focus group questionnaire fundamentals - basic questions. Available from http://www.focus grouptips.com/focus group questionnaire.html. [Accessed: 19 October 2016]

HUGO, AJ. 2017. Language as an Excluding Factor in the South African School System. In Inclusive Education in African Contexts (115-128). Sense Publishers: Rotterdam.

JOHNSON, K, E DEMPSTER \& W HUGO. 2015. Exploring the recontextualization of biology in the CAPS for life sciences. Journal of Education, 60: 101-121.

KIPO, DD. 2013. Mixed research methods: Reflections on social public policy. Asian Social Science, 9(17): 259.

LEDERMAN, NG, JS LEDERMAN, BS KIM, \& EK KO. 2006. Project ICAN: A Program To Enhance Teachers' And Students' Understandings of Nature of Science and Scientific Inquiry. SAARMSTE EXECUTIVE, 451.

MDOLO, M \& M DOIDGE. 2011. Factors that affect the implementation of a new biology curriculum in Malawi. Marang Centre for Mathematics and Science Education, University of Witwatersrand, Johannesburg, South Africa: 299-317.

MEYER, X \& BA CRAWFORD. 2009. Being explicit about Science: Instruction in the nature of Science as a multicultural approach. Paper presented at the annual meeting of NARST, Garden Grove, California. 
PFEIFFER, V. 2018. Literacies: skills and practices in developing a writing identity. Per Linguam: A Journal of Language Learning/Per Linguam: Tydskrif vir Taalaanleer, 34(1): 60-76.

PRINSLOO, CH, SC ROGERS \& JC HARVEY. 2018. The impact of language factors on learner achievement in Science. South African Journal of Education, 38(1):1-14

PROBYN, M. 2009. 'Smuggling the vernacular into the classroom': conflicts and tensions in classroom code-switching in township/rural schools in South Africa. International Journal of Bilingual Education and Bilingualism, 12(2): 123-136.

ROSE, S \& O VAN DULM. 2006. Functions of code-switching in multilingual classrooms. Per Linguam: a Journal of Language Learning/Per Linguam: Tydskrif vir Taalaanleer, 22(2): $1-13$.

SALDANA, J. 2016. The coding manual for qualitative researchers. Britain: Ashford.

SPAULL, N. 2013. Languages of learning in South Africa. Available from https:nicspaull.com/2013/10/27/languages-of-learning-in-South-Africa) [Accessed: 14 August 2018].

TAYLOR, S \& M Coetzee. 2013. Mother-tongue classrooms give a better boost to English study later. Mail \& Guardian, 18 October. Available at http://mg.co.za/article/2013-10-18mother-tongueclassrooms-give-a-better-boost-to-english-studylater. Accessed 25 June 2015

TAYLOR, S \& M VON FINTEL. 2016. Estimating the impact of the language of instruction in South African primary schools: A fixed effects approach. Economics of Education Review, 50: 75-89.

WELLINGTON, J \& J OSBORNE. 2001. Language and literacy in science education. UK: McGraw-Hill Education.

YIN, RK. 2012. Applications of case study research. Thousand Oaks: Sage.

\section{BIOGRAPHICAL NOTE}

Florah Moleko Teane is a Senior Lecturer at the University of South Africa. Her job description entails providing support and tuition to honors and Masters Students, doing research (Published book chapters, Conference proceedings and Articles) and coordinating an outreach program for the community. She completed her PhD in 2014 specializing in Curriculum studies. 